\title{
STUDI FENOMENOLOGI: PENGALAMAN AKTIVITAS FISIK KLIEN YANG MENJALANI HEMODIALISIS
}

\author{
Rosiah $^{1}$, Shofa Chasani ${ }^{2}$, Wahyu Hidayati ${ }^{3}$ \\ ${ }^{1,2,3}$ Program Studi Magister Keperawatan \\ Fakultas Kedokteran Universitas Diponegoro \\ Email: rosrosiah82@gmail.com
}

\begin{abstract}
Abstrak
Hemodialisis merupakan salah satu terapi yang dilaksanakan oleh klien dengan penyakit ginjal kronis stadium akhir. Berbagai perubahan fisik dan psikologis klien yang menjalani hemodialisis berpengaruh pada kemampuan klien dalam melakukan aktivitas fisik. Pengalaman klien yang menjalani hemodialisis dalam melakukan aktivitas fisik merupakan hal penting untuk diketahui agar dapat menjadi dasar pengembangan program intervensi untuk mengurangi resiko komplikasi penyakit jantung yang menjadi penyebab utama kematian penyakit ini. Tujuan penelitian ini yaitu mengeksplorasi secara mendalam pengalaman pemenuhan kebutuhan aktivitas fisik klien yang menjalani hemodialisis. Metode yang digunakan dalam penelitian ini yaitu kualitatif dengan pendekatan fenomenologi. Data dikumpulkan melalui in-depth interview kepada 8 (delapan) orang klien yang menjalani hemodialisis. Keabsahan data meliputi credibility, dependability, confirmability, transferability. Teknik analisis data menggunakan metode Collaizi. Hasil penelitian didapatkan tema yaitu: (1) Perubahan pemenuhan kebutuhan aktivitas selama menjalani hemodialisis; (2) Mempertahankan kemampuan perawatan diri selama menjalani hemodialisis. Hasil penelitian pengalaman aktivitas fisik klien yang menjalani hemodialis dapat dijadikan dasar pengembangan program pelayanan keperawatan yang lebih bermutu untuk dapat meningkatkan produktivitas klien sehingga kualitas hidup klien hemodialisis menjadi lebih baik.
\end{abstract}

Kata kunci: pengalaman, aktivitas fisik, hemodialisis

\begin{abstract}
Hemodialysis is a treatment that is carried by client with end-stage chronic kidney disease. Various physical and psychological changes of patients who undergo hemodialysis affect the client's ability to perform physical activities. Experiences of patients who undergo hemodialysis in performing physical activities are important to note. They can be the basis for development of intervention programs to reduce the risk of heart disease complications that are the leading cause of death of patients with kidney disease. The purpose of this research is to explore the experience of meeting the needs of the physical activities of patients undergoing hemodialysis. The method used in this research is qualitative with phenomenological approach. The data were collected through in-depth interviews to eight (8) patients who undergo hemodialysis. The data validity includes credibility, dependability, confirmability, and transferability. The data were analyzed by using Collaizi method. The results of the study reveal 1) Changes of activity during hemodialysis; 2) The ability of self-care while undergoing hemodialysis. The results of the research can be used as the basis for the development of better nursing care to increase client's productivity so that the life quality of client can be enhanced.
\end{abstract}

Keywords: Experience, Physical Activity, Hemodialysis 


\section{PENDAHULUAN}

Penyakit ginjal kronis (PGK) atau Chronic Kidney Disease merupakan salah satu masalah kesehatan yang menjadi perhatian publik, penyakit ginjal ini bersifat progresif dan irreversible dapat berkembang menjadi end stage renal disease (ESRD). Penanganan klien penyakit ginjal kronis bertujuan untuk mempertahankan fungsi ginjal, dan apabila PGK berkembang menjadi ESRD maka diperlukan terapi pengganti ginjal salah satunya hemodialisis (National Chronic Kidney Disease Fact Sheet. 2014; Vivekanand Jha, et al. 2013).

Kondisi ini akan mempengaruhi toleransi aktivitas klien penyakit ginjal kronis yang menjalani hemodialisis. Aktivitas merupakan salah satu kebutuhan dasar manusia yang harus dipenuhi untuk mempertahankan homeostasis tubuh. Pola Fungsional Kesehatan Gordon menjelaskan tentang pentingnya aktivitas dan latihan berpengaruh pada kesehatan fungsi pernapasan dan sirkulasi (Potter and Perry, 2005; Alligood, 2014).

Kemampuan seseorang dalam melakukan aktivitas merupakan salah satu tanda baik status kesehatan. Aktivitas fisik yang teratur bermanfaat pada kesehatan yang meliputi terhindar dari beberapa penyakit seperti penyakit kardiovaskuler, stroke, diabetes; mempertahankan berat badan seimbang, meningkatkan kekuatan dan kelenturan otot.

Aktivitas fisik adalah gerakan tubuh yang dihasilkan oleh otot rangka yang memerlukan pengeluaran energi. Menurut WHO (2010) kurangnya aktivitas fisik telah diidentifikasi sebesar 20\%-30\% sebagai faktor risiko independen untuk penyakit kronis dan diperkirakan sebagai penyebab kematian secara global.
Beberapa penelitian menyebutkan bahwa tingkat aktivitas fisik pada klien yang menjalani hemodialisis berada pada rentang 20\%-50\% lebih rendah, penurunan aktivitas fisik ini dipengaruhi oleh faktor buruknya kondisi kesehatan klien, kurangnya kesadaran melakukan aktivitas fisik, dan faktor depresi (Johansen, 2000; Sander, et al., 2011).

Klien yang kurang atau tidak beraktivitas akan meningkatkan morbiditas dan mortalitas berupa peningkatan resiko penyakit kardiovaskuler. Menurut Pernefri (2012) penyakit kardiovaskuler merupakan penyebab tertinggi kematian pada penderita penyakit ginjal kronis yang menjalani hemodialisi di Indonesia.

Penelitian kualitatif pada 7 klien hemodialisis oleh Krueger pada tahun 2009 menghasilkan tema kesedihan. Kesedihan yang dialami klien disebabkan karena kelemahan dan kelelahan sehingga klien mengalami ketidakmampuan berpartisipasi dalam kegiatan dan melaksanakan peran serta tanggung jawabnya.

Berbagai penelitian tentang aktivitas dan latihan telah banyak menjelaskan manfaat yang dapat dirasakan oleh klien yang menjalani hemodialisis, namun demikian masih banyak klien enggan bahkan tidak mau melakukan aktivitas dan latihan fisik. Peningkatan penyakit kardiovaskuler pada klien hemodialisis sebagai akibat kurangnya aktivitas fisik harus mendapatkan perhatian dari perawat yang menjalankan asuhan keperawatan komprehensif diantaranya pengkajian pemenuhan kebutuhan aktivitas sehingga dapat disusun intervensi program aktivitas yang sesuai dengan kondisi klien.

Peran perawat sebagai care provider harus mampu memberikan asuhan keperawatan yang komprehensif, tidak hanya berfokus pada status hemodinamik klien namun 
perawat dapat memfasilitasi pemenuhan kebutuhan aktivitas fisik agar klien dapat meningkat status kesehatannya dan lebih produktif sehingga dapat meningkat kualitas hidupnya.

Penelitian tentang aktivitas fisik klien yang menjalani hemodialisis di Indonesia telah banyak dilakukan dengan metode kuantitatif, sehingga peneliti merasa perlu mengeksplorasi dan memahami fenomena pengalaman klien dalam pemenuhan kebutuhan aktivitas fisik melalui metode kualitatif. Berdasarkan uraian di atas maka dapat dirumuskan masalah penelitian: "Bagaimana pengalaman pemenuhan kebutuhan aktivitas fisik klien penyakit ginjal kronis yang menjalani hemodialisis.

Penelitian ini bertujuan untuk mengeksplorasi secara mendalam pengalaman pemenuhan kebutuhan aktivitas fisik klien yang menjalani hemodialisis.

\section{METODE PENELITIAN}

Penelitian ini menggunakan metode kualitatif dengan pendekatan fenomenologi yang bertujuan untuk mengeksplorasi pemenuhan kebutuhan aktivitas klien penyakit ginjal kronis yang menjalani hemodialisis sesuai dengan pengalaman klien.

Populasi dalam penelitian ini yaitu klien dengan penyakit ginjal kronis yang menjalani hemodialisis di Unit Hemodialisis Rumah Sakit Umum Daerah Kelas B Kabupaten Subang. Partisipan diseleksi berdasarkan informasi dari penanggungjawab dan kepala perawatan unit hemodialisa sesuai dengan kriteria penelitian. Kriteria inklusi sebagai persyaratan dalam penelitian ini yaitu : 1) Klien telah menjalani hemodialisis lebih dari 1 (satu) tahun; 2) Usia klien antara $30-65$ tahun; 3) Klien tidak mengalami kelainan muskuloskeletal dan komplikasi lain yang akan menyebabkan keterbatasan aktivitas.
Alat pengumpulan data dalam penelitian ini adalah peneliti sendiri sebagai instrumen utama. Pengumpulan data dilakukan dengan menggunakan alat bantu berupa data biografi, status medis, beberapa pertanyaan tertulis sebagai pedoman wawancara, alat tulis, dan alat perekam untuk merekam wawancara peneliti terhadap partisipan.

Penelitian dilaksanakan di unit hemodialisis RSUD Kelas B Kabupaten Subang, dengan prosedur penelitian dimulai dari tahap perijinan, tahap pengumpulan data dan tahap penutup. Selama penelitian berlangsung peneliti menerapkan prinsip etik penelitian yaitu menghargai harkat dan martabat partisipan, memperhatikan kesejahteraan partisipan, dan memperhatikan prinsip keadilan.

Analisis data dilakukan setelah memutar hasil rekaman, mencatat semua pembicaraan dalam rekaman, menuliskan catatan lapangan, dan memindahkan hasil wawancara ke dalam bentuk tulisan sehingga didapatkan bentuk transkrip verbatim. Untuk mendapatkan kaakuratan transkrip yang ada maka dilakukan pengulangan mendengarkan rekaman wawancara sambil membaca transkrip. Kemudian peneliti menyimpan data dalam bentuk file di komputer, flash disc dan compact disc serta email peneliti, hal ini dilakukan untuk menghindari kehilangan data. Analisis data dalam penelitian ini menggunakan metode Colaizzi. Keabsahan data terdiri dari 4 (empat) kriteria yaitu: derajat kepercayaan, kebergantungan, kepastian, dan keteralihan (Afiyanti and Rachmawati, 2014).

\section{Etik dan tata kelola penelitian}

Persetujuan etik diberikan oleh Komite etik penelitian kesehatan Fakultas Kedokteran Universitas Diponegoro dan Rumah Sakit Umum Pusat Kariadi Semarang. 


\section{HASIL PENELITIAN}

Tabel 1.

Data Demografi Partisipan

\begin{tabular}{ccccc}
\hline Partisipan & $\begin{array}{c}\text { Umur } \\
\text { (tahun) }\end{array}$ & Jenis kelamin & Pekerjaan & Pendidikan \\
\hline P1 & 43 & Laki-laki (L) & Dosen & Strata 2 \\
P2 & 46 & L & Wiraswasta & SMA \\
P3 & 50 & Perempuan (P) & Ibu Rumah Tangga (IRT) & SD \\
P4 & 6 & L & Pensiunan & Diploma 3 \\
P5 & 44 & P & IRT & SMA \\
P6 & 47 & P & IRT & SMP \\
P7 & 48 & P & IRT & Strata 1 \\
P8 & 47 & P & IRT & Strata 1 \\
\hline
\end{tabular}

Tabel 2.

Status Kesehatan Partisipan

\begin{tabular}{|c|c|c|c|c|}
\hline Partisipan & Frekuensi HD & $\begin{array}{c}\text { Lamanya } \\
\text { HD }\end{array}$ & $\begin{array}{c}\text { Riwayat } \\
\text { Penyakit } \\
\text { sebelumnya }\end{array}$ & Komplikasi \\
\hline P1 & $2 \mathrm{x}$ seminggu & 4 tahun & Hipertensi & $\begin{array}{c}\text { Efusi pleura, } \\
\text { Asites, Cardiomegali }\end{array}$ \\
\hline $\mathrm{P} 2$ & $2 \mathrm{x}$ seminggu & 5 tahun & Batu ginjal & Asites, Cardiomegali \\
\hline P3 & $2 \mathrm{x}$ seminggu & 4 tahun & Hipertensi & Cardiomegali \\
\hline P4 & $2 \mathrm{x}$ seminggu & 9 tahun & Batu ginjal & Cardiomegali \\
\hline P5 & $2 \mathrm{x}$ seminggu & 3 tahun & Hipertensi & Cardiomegali \\
\hline P6 & $2 \mathrm{x}$ seminggu & 1,5 tahun & Hipertensi & Asites, Cardiomegali \\
\hline P7 & $2 \mathrm{x}$ seminggu & 3 tahun & Hipertensi & Cardiomegali \\
\hline P8 & $2 \mathrm{x}$ seminggu & 4,5 tahun & Batu ginjal & Cardiomegali \\
\hline
\end{tabular}

Analisis tematik mengidentifikasi 2 tema yaitu: (1) Perubahan pemenuhan kebutuhan aktivitas selama menjalani hemodialisis; (2) Kemampuan dalam perawatan diri selama menjalani hemodialis.

Tabel 3.

Perubahan Pemenuhan Kebutuhan Aktivitas Selama Menjalani Hemodialisis

\begin{tabular}{lll}
\hline \multicolumn{1}{c}{ Kategori } & \multicolumn{1}{c}{ Sub tema } & \multicolumn{1}{c}{ Tema } \\
\hline a. Hampir di off berkaitan dengan otot & & \\
b. Mengurangi kegiatan aktivitas harian & & \\
c. Aktivitas sudah berkurang & Kemampuan aktivitas & \\
d. Aktivitas terbatas & menurun & Perubahan pemenuhan \\
e. Tidur istirahat & & kebutuhan aktivitas selama \\
f. Tidak bebas beraktivitas & & \\
g. Penurunan aktivitas seksual & & \\
\hline a. Makukan kegiatan sendiri & & \\
b. Aktivitas sehari-hari normal & & \\
c. Melakukan sendiri apapun itu pekerjaan & Mempertahankan \\
d. Masih tetap bisa aktivitas & aktivitas & \\
e. Melakukan aktivitas rumah tangga & & \\
f. Senam & & \\
\hline
\end{tabular}




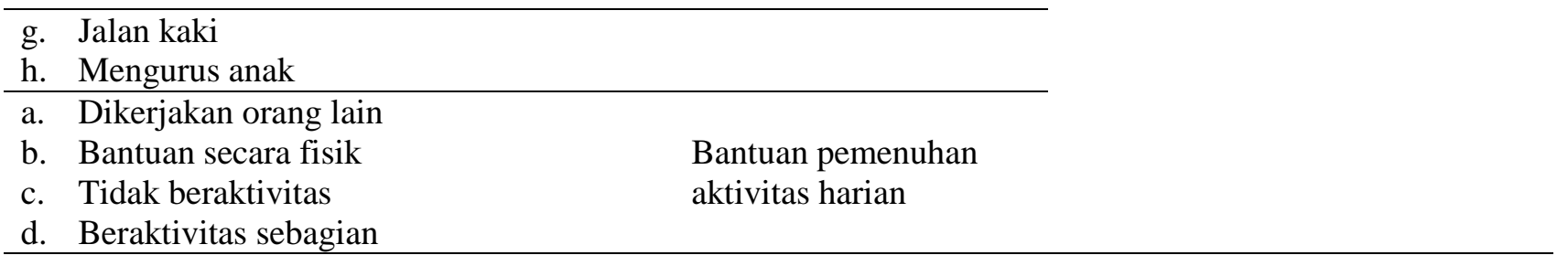

Tabel 4.

Kemampuan dalam Perawatan Diri Selama Menjalani Hemodialis

\begin{tabular}{llcc}
\hline \multicolumn{2}{c}{ Kategori } & Sub tema & Tema \\
\hline a. & $\begin{array}{l}\text { Mandi, ke toilet, menggunakan baju } \\
\text { sendiri bisa }\end{array}$ & & Kemampuan dalam perawatan diri \\
b. Sendiri ke kamar mandi. & Kemandirian self care & $\begin{array}{c}\text { Kelama menjalani hemodialis } \\
\text { c. Mandi, nyuci sendiri }\end{array}$ & \\
d. Bisa sendiri & & \\
\hline
\end{tabular}

Perubahan aktivitas pada partisipan yaitu terjadinya penurunan kemampuan aktivitas, namun kondisi ini tidak dibiarkan berlanjut. Partisipan berupaya untuk dapat mempertahankan kemampuan aktivitasnya sesuai dengan kemampuannya melalui kemandirian dalam pemenuhan kebutuhan perawatan diri.

\section{PEMBAHASAN}

\section{Perubahan Aktivitas Selama Menjalani Hemodialisis}

Kemampuan partisipan dalam beraktivitas mengalami perubahan saat sebelum sakit dan setelah sakit maupun selama menjalani hemodialisis. Beberapa partisipan mengalami perubahan dalam beraktivitas karena mengalami beberapa keluhan yang menurunkan kemampuan aktivitas sehari-hari.

Berbagai perubahan fisik yang dialami partisipan berpengaruh terhadap kemampuan aktivitas partisipan. Beberapa partisipan masih dapat mempertahankan aktivitasnya dengan melakukan kegiatan-kegiatan sesuai dengan kemampuannya misalnya melakukan aktivitas rumah tangga, seperti salah satu pernyataan partisipan berikut ini:

"Iya sendiri, iya apapun itu pekerjaan, ibu ke rumah sakit ibu kerjakan sendiri ... Ibu masih bisa aktivitas. Ibu masih bisa nyuci, nyapu halaman." (P3)
Klien dengan penyakit ginjal kronis dan menjalani hemodialisis akan mempengaruhi seluruh sistem tubuh yang berdampak pada kemampuan aktivitasnya. Kemampuan aktivitas klien hemodialisis yang menurun disebabkan berbagai kondisi akibat penyakit yang dialaminya dan terapi yang dijalaninya (Smeltzer \& Bare, 2010).

Tingkat aktivitas fisik pada klien yang menjalani hemodialisis berada pada rentang 20\%-50\% lebih rendah, penurunan aktivitas fisik ini dipengaruhi oleh faktor buruknya kondisi kesehatan klien, kurangnya kesadaran melakukan aktivitas fisik, dan faktor psikologis yaitu depresi (Johansen, 2000). Kondisi klinis yang berpengaruh terhadap aktivitas fisik diantaranya diagnosis dan penanganan penyakit yang dialami, gejalagejala penyakit yang dialami, status fungsional fisik, dan efek samping penanganan yang dijalani (Parson, et al. 2006).

Penelitian lain menjelaskan bahwa kualitas hidup klien penyakit ginjal kronis yang 
menjalani hemodialisis secara fisik menurun dimana terjadi penurunan kapasitas fungsional dan keterbatasan aktivitas akibat kelemahan sehingga klien penyakit ginjal kronis kurang melakukan aktivitas fisik bahkan beberapa klien melaporkan tidak beraktivitas (Cheema et al. 2005; O'Hare, et al. 2003).

Penurunan kemampuan aktivitas pada klien hemodialisis dipengaruhi berbagai perubahan fisik dan psikologis akibat penyakit yang yang dialaminya. Perubahan kemampuan aktivitas ini berbeda pada tiap individu, hal ini dipengaruhi oleh status kesehatan dan riwayat penyakit sebelumnya.

Perubahan aktivitas yang terjadi pada klien hemodialisis ini memerlukan suatu perencanaan upaya pemenuhan kebutuhan aktivitas. Salah satunya dengan memberikan bantuan terhadap klien hemodialisis dalam pemenuhan kebutuhan aktivitas klien yang dianggap berat atau dengan melakukan aktivitas sesuai dengan kemampuan yang dimiliki klien.

\section{Mempertahankan Kemampuan Perawatan Diri Selama Menjalani Hemodialis}

Kemampuan dalam perawatan diri selama menjalani hemodialisis berbeda tergantung dari tingkat energi yang dimiliki oleh partisipan. Keseluruhan partisipan yang diwawancarai mengungkapkan bahwa aktivitas perawatan diri masih dapat dilakukan tanpa bantuan orang lain. Hal ini seperti ungkapan partisipan berikut ini:

"Masih sendiri da masih kuat. Sendiri perawatan diri mah ga dibantu sama orang lain" (P8)

Berbeda dengan hasil penelitian Atashpeikar, et al. (2012) dihasilkan bahwa pasien hemodialisis tidak memiliki kemampuan yang penuh dalam self-care, kemampuan ini dipengaruhi oleh akses vaskuler dan diet.

Kemandirian aktivitas perawatan diri yang dimiliki partisipan disebabkan karena pandangan partisipan bahwa apapun kondisinya untuk pemenuhan kebutuhan perawatan diri diupayakan harus dapat dilakukan sendiri sebagai aktualisasi diri individu yang mampu memenuhi kebutuhan dirinya sendiri sehingga dapat meningkatkan kepercayaan diri.

Perawatan diri klien terpenuhi secara adekuat atas keinginan sendiri untuk dapat mandiri dalam memenuhi kebutuhan pribadinya. Beberapa keluarga bahkan menganjurkan untuk tidak beraktivitas, seperti ungkapan partisipan berikut ini:

“ ... anak - anak suka bilang sini mah $k u$ Eneng saja, biarin ibu ga mau terlalu merepotkan" (P3)

Kondisi seperti ini kemungkinan dilatarbelakangi oleh kurangnya informasi yang didapatkan keluarga dalam merawat klien hemodialisis. Masalah ini menjadi perhatian yang harus ditindaklanjuti guna mempertahankan aktivitas klien hemodialisis dengan pemberian informasi yang terkait kebutuhan aktivitas klien dan peningkatan motivasi klien dalam mempertahankan kebutuhan aktivitasnya.

\section{KESIMPULAN}

Berbagai keterbatasan yang dialami klien yang menjalani hemodialisis mempengaruhi terhadap kemampuan aktivitas fisik. Perubahan yang terjadi pada klien yang menjalani hemodialisis ini menuntut klien untuk tetap berupaya mempertahankan kemampuan aktivitasnya. Pemenuhan kebutuhan aktivitas klien hemodialisis ini harus menjadi perhatian seluruh sistem pendukung. 


\section{DAFTAR PUSTAKA}

A.M. O'Hare, K. Towney, P. Bacchetti, K.L. Johansen. (2003). Decreased Survival Among Sedentary Patients Undergoing Dialysis: Result form the Dialysis Morbidity and Mortality Study Wave 2, Am J Kidney Dis, Vol. 41.

Afiyanti, Yati. Rachmawati, Imami Nur. (2014). Metodologi Penelitian Kualitatif dalam Keperawatan. Jakarta: Rajawali Pers.

Alligood, Martha Raile. (2014). Nursing Theorist and their Work, Edition 8. Elsavier Mosby; St. Louis, Missouri.

Atashpeikar, Soulmaz. Jalilazar, Tahereh. Heidarzadeh, Mehdi. (2012). SelfCare Ability in Hemodialysis Patients. Journal of Caring Sciences, 1(1), 31.

Baraz S., Mohammadi E., Broumand B. (2005). The Effect of Self - Care Educational Program on Decreasing the Problems and Improving the Quality of Life of Dialysis Patients. Journal of Hayat; 11 (2 and 1) :51-62 URL http://hayat. tums.ac.ir/article-1-238en.html.

Cheema, Birinder Singh B. Singh, Maria A. Fiatarone. (2005). Exercise Training in Patients Receiving Maintenance Hemodialysis: A Systematic Review of Clinical Trials.

Hidayati, Wahyu. (2013). Metode Perawatan Pasien Gangguan Sistem Perkemihan: Aplikasi Konsep Orem "Self care deficit" dan Studi Kasus. Penerbit Kencana: Jakarta.

KL. Johansen, et al. (2000). Physical Activity Levels in Patients on Hemodialysis and Healty Sedentary Control, Kidney Int, Vol 57.
National Center for Chronic Disease Prevention and Health Promotion. (2014). National Chronic Kidney Disease Fact Sheet.

National Kidney Foundation. (2006). KDOQI Clinical Practice Guidelines and Clinical Practice Recommendations for 2006 Updates: Hemodialysis Adequacy, Peritoneal Dialysis Adequacy and Vascular Access. Am J Kidney Dis 48:S1-S322.

Parson, TK. Tosselmire, ED. King-Van Vlack, CE. (2006). Exercise Training During Hemodialysis Improve Dialysis Efficacy and Physical Performance, Exercise arch Phys Med Rehabil : $87: 680-7$.

Perkumpulan Nefrologi Indonesia. (2012). Program Indonesia Renal Registry.

Potter, P.A. \& Perry, A.G. (2005). Fundamental of Nursing Concept, Process and Practice. $4^{\text {th }}$ edition. St. Louis: Mosby Company.

Sander, Antoinette P. Wilson,Jessica. Izzo, Nicole. Mountford, Stephanie A. Hayes, Karen W. (2011). Factors that Affect Decisions about Physical Activity and Exercise in Survivors of Breast Cancer: A Qualitative Study.

Smeltzer, SC; et.al. (2010). Brunner \& Suddarth Textbook of Medical Surgical Nursing. Philadelphia : Lippincots.

Tomayko, Emily. (2012). Diet and Lifestyle Interventions to Improve Comorbidconditions of Chronic Kidney Disease. ProQuest LLC UMI 3503874.

Vivekanand Jha,Guillermo Garcia-Garcia, Kunitoshi Iseki,Zuo Li, Saraladevi Naicker, Brett Plattner, Rajiv Saran,Angela Yee-Moon Wang, ChihWei Yang. (2013). Chronic Kidney 
Disease: Global Dimension and Perspectives. Global Health DOI: http://dx.doi.org/10.1016/S0140-6736 (13)60687-X. Volume 382, No. 9888, p260-272.

William G Couser; Giuseppe Remuzzi; Shanthi Mendis; Marcello Tonelli. (2011). Chronic Kidney Disease: the Global Perspective. Kidney Int. 80(12): 1258-1270.
World Health Organization. (2010). Global Recommendations on Physical Activity for Health. WHO Press, Geneva Switzerland. 